\title{
CAPÍTULO 20: QUEIJO FRESCO ARTESANAL DE LEITE DE CABRA ADICIONADO DE BETERRABA: VERIFICAÇÃO DO POTENCIAL PROBIÓTICO E CARACTERIZAÇÃO Fİ́SICO-QUÍMICA
}

\author{
CAPÍTULO 20: QUESO ARTESANAL DE LECHE DE CABRA FRESCO CON \\ REMOLACHA: VERIFICACIÓN DEL POTENCIAL PROBIÓTICO Y \\ CARACTERIZACIÓN FÍSICO-QUÍMICA
}

\section{CHAPTER 20: ARTISANAL SOFT GOAT MILK CHEESE WITH BEET: VERIFICATION OF THE PROBIOTIC POTENTIAL AND PHYSICAL-CHEMICAL CHARACTERIZATION}

\author{
Gabriel Cicalese Bevilaqua ${ }^{1}$; Graciliane Nobre da Cruz Ximenes ${ }^{2}$; Neila Mello dos Santos Cortez ${ }^{3}$
}

DOI:https://doi.org/10.31692/978-65-88970-17-1.290-306

\begin{abstract}
RESUMO
O leite de cabra, quando comparado com o bovino, apresenta parâmetros nutricionais superiores, porém possui uma menor aceitação por consumidores não habituados. O desenvolvimento de novos produtos que aliem o interesse do consumidor aos produtos de cabra é uma forma de valorizar essa matéria-prima. $\mathrm{O}$ presente trabalho objetivou caracterizar um novo queijo fresco artesanal de leite de cabra cru adicionado de concentrado de beterraba, desenvolvido com e sem a inoculação de uma cultura probiótica de Lactobacillus acidophilus, QS e QP, respectivamente. Foram realizados ensaios físico-químicos de $\mathrm{pH}$, acidez titulável, lipídios e proteínas. Executou-se, nos produtos finais, ensaios microbiológicos de indicadores e patógenos e a contagem de Bactérias Láticas (BL) semanalmente por 35 dias, cujo crescimento foi ajustado matematicamente ao modelo de Baranyi e Roberts pelo programa online $\mathrm{DMFit}^{\circledR}$. Através dos resultados, observou-se que os queijos produzidos puderam ser classificados como semigordos $(\mathrm{QS}=37,00 \%$ e QP $=34,00 \%$ de gordura no extrato seco) e de alta a muito alta umidade $(\mathrm{QS}=57,60 \%$ de água; $\mathrm{QP}=54,80 \%$ de água). Da contagem de $\mathrm{BL}$, foram obtidas quantidades nas ordens de $10^{11}$ e $10^{12} \mathrm{UFC} / \mathrm{g}$ após 35 dias, possibilitando a caracterização dos produtos como probióticos $\left(>10^{7} \mathrm{UFC} / \mathrm{g}\right)$. Além disso, pelo ajuste matemático, percebeu-se que BL no queijo sem adição de probióticos apresentaram uma maior taxa de crescimento e estabilizaram-se em valores superiores de concentração de microrganismos. Devido ao comportamento das Bactérias Láticas, notou-se também que a adição da cultura probiótica de L. acidophilus não foi necessária para caracterizar o queijo como probiótico, pois essa característica foi evidenciada através da microbiota endógena do leite caprino cru, preservada no queijo artesanal produzido.
\end{abstract}

Palavras-Chave: Bactérias láticas, Leite caprino cru, Microbiologia preditiva, Queijos com vegetais.

\section{RESUMEN}

La leche de cabra, en comparación con la de bovino, presenta parámetros nutricionales superiores, pero tiene menos aceptación por parte de consumidores poco habituales. Nuevos productos que combinen el interés del consumidor con los productos caprinos es una forma de potenciar esta materia prima. El presente trabajo tuvo como objetivo caracterizar un nuevo queso artesano fresco a partir de leche de cabra añadido con concentrado de remolacha, con y sin la inoculación de un cultivo probiótico de Lactobacillus acidophilus, llamados de QP y QS, respectivamente. Se realizaron análisis físicos y químicos de $\mathrm{pH}$, acidez titulable, lípidos y proteínas. Se realizaron pruebas microbiológicas de indicadores y patógenos y el conteo de Bacterias Lácticas (BL) semanalmente durante 35 días, cuyo crecimiento fue ajustado matemáticamente al modelo de Baranyi y Roberts por el programa en línea DMFit ${ }^{\circledR}$. Con los resultados, se observó que los quesos elaborados podrían clasificarse como semigrasos $(\mathrm{QS}=37,00 \%$ y $\mathrm{QP}=34,00 \%$ de grasa en el extracto seco) y de alta a muy alta humedad $(\mathrm{QS}=57,60 \%$

\footnotetext{
${ }^{1}$ Engenheiro de Alimentos, Universidade Federal de Pernambuco, gabriel.cicalese@gmail.com.br

${ }^{2}$ Mestre em Agronomia, Universidade Federal de Pernambuco, gracilianeximenes@ uol.com.br

${ }^{3}$ Professora Doutora em Medicina Veterinária, Universidade Federal de Pernambuco, neila.mello@ufpe.br
} 
de água; $\mathrm{QP}=54,80 \%$ de água). Del recuento de $\mathrm{BL}$, se obtuvieron cantidades de $10^{11}$ y $10^{12} \mathrm{UFC} / \mathrm{g}$ después de 35 días, lo que permitió caracterizar los productos como probióticos $\left(>10^{7} \mathrm{UFC} / \mathrm{g}\right)$. Por el ajuste matemático, BL en el queso sin la adición de probióticos mostraron una mayor tasa de crecimiento y se estabilizaron a mayores valores de concentración. Debido al comportamiento de las Bacterias Lácticas, también se observó que la adición del cultivo probiótico de L. acidophilus no fue necesaria para caracterizar el queso como probiótico, ya que esta característica fue evidenciada a través del microbiota endógeno de la leche cruda de cabra, conservada en el queso artesanal elaborado.

Palabras Clave: Bacterias lácticas; Leche cruda de cabra; Microbiología predictiva; Quesos con verduras.

\begin{abstract}
Goat milk, when compared to bovine, has superior nutritional parameters, but it has less acceptance by unaccustomed consumers. The development of new goat products that combine the consumer interests is a way to enhance this raw material. This present work aimed to characterize a new soft artisan cheese of goat milk added with beet concentrate, developed with and without the inoculation of a probiotic culture of Lactobacillus acidophilus, denominated QP and QS, respectively. Physical and chemical analyzes of $\mathrm{pH}$, titratable acidity, lipids and proteins were performed. Microbiological tests of indicators and pathogens and the counting of Lactic Bacteria (BL) were performed weekly for 35 days, whose growth was mathematically adjusted to the Baranyi and Roberts model by the online program DMFit ${ }^{\circledR}$. Through the results, it was observed that the cheeses produced could be classified as semi-fat $(\mathrm{QP}=$ $34,00 \%$ and $\mathrm{QS}=37,00 \%$ of fat in the dry extract) and from high to very high humidity (QS $=57,60 \%$ and $\mathrm{QP}=54,80 \%$ of water). From the BL count, quantities of $10^{11}$ and $10^{12} \mathrm{CFU} / \mathrm{g}$ were obtained after 35 days, enabling the characterization of both products as probiotic $\left(>10^{7} \mathrm{CFU} / \mathrm{g}\right)$. In addition, due to the mathematical adjustment, it was noticed that BL in the cheese without the addition of probiotics showed a higher growth rate and stabilized at higher values of concentration of microorganisms. Due to the behavior of the Lactic Bacteria, it was also noted that the addition of the probiotic culture was not necessary to characterize the cheese as probiotic, as this characteristic was evidenced through the endogenous microbiota of raw goat milk, preserved in the artisanal cheese produced.
\end{abstract}

Keywords: Cheese with vegetables; Lactic bacteria; Predictive microbiology; Raw goat milk.

\title{
INTRODUÇÃO
}

O leite de cabra, uma das matérias primas possíveis na produção de queijos, quando comparado ao leite bovino, apresenta relevantes qualidades nutricionais, sendo rico em proteínas, vitaminas e minerais (PARK, 2017). Por outro lado, essa matéria prima apresenta sabor e aroma típicos dos produtos de cabra, que podem influenciar negativamente na aceitação do leite caprino e dos seus derivados por consumidores que não estão habituados aos mesmos (COSTA et al., 2015; QUEIROGA et al., 2013).

Um dos queijos mais produzidos com o leite de cabra é o queijo de coalho, um queijo fresco de ampla aceitação e com produção tradicional nordestina a partir de leite cru ou pasteurizado (QUEIROGA et al., 2013). Quando fabricado com leite cru, o queijo de coalho recebe a denominação de artesanal e tem como principal diferencial a presença de Bactérias Láticas (BL) oriundas do leite. Essas bactérias originam aspectos sensoriais diferenciados além de produzirem metabólitos, como as bacteriocinas, antimicrobianos que possuem efeito positivo na conservação do produto e na promoção da saúde do consumidor (ALMEIDA JÚNIOR et al., 
2015).

O desenvolvimento de novos produtos e incorporação de condimentos ao queijo de coalho de cabra é uma alternativa que vem sendo utilizada para aumentar a aceitação sensorial e a valorização desse produto (APOSTU et al., 2014; SILVA; COSTA; DELFINO, 2018). Além disso, a demanda atual do consumidor por alimentos funcionais e nutricionais leva a indústria a desenvolver estratégias para tornar os produtos mais atrativos no mercado, como a utilização do leite cru e a adição de culturas probióticas, que são microrganismos vivos que promovem o equilíbrio microbiano intestinal, afetando positivamente a saúde do indivíduo (LIMA et al., 2017; MARTINS et al., 2018).

No intuito de produzir um novo queijo artesanal de leite de cabra, a beterraba (Beta vulgaris L.) pode ser introduzida como um vegetal que possui elevados teores de açúcares, fibras alimentares, proteínas, minerais e um reduzido valor de lipídios (SARTORIO et al., 2016). Além disso, esse vegetal possui betalaínas, pigmentos não tóxicos que caracterizam a coloração vermelha típica do vegetal. Assim, a incorporação desse vegetal em produtos alimentares pode trazer um benefício nutricional além de ser um fator diferencial na aparência de produtos, podendo torná-los mais atrativos ao consumidor (SLATNAR et al., 2015).

De forma a explorar a microbiota oriunda do leite cru e de introduzir culturas probióticas no produto a ser desenvolvido, a microbiologia preditiva possui papel fundamental, pois é um método rápido e relativamente econômico para a obtenção de estimativas confiáveis quanto ao crescimento, inativação e sobrevivência dos microrganismos em condições específicas (SIQUEIRA et al., 2014).

Com a validação de um modelo matemático que caracterize o crescimento dos microrganismos de interesse em um novo produto produzido, é possível utilizar a microbiologia preditiva para estimar o período em que o número de microrganismos atende ao esperado e observar o comportamento do microrganismo com o tempo (FAKRUDDIN; MAZUMDAR; MANNAN, 2012).

Nesse contexto, o presente trabalho objetivou desenvolver um novo queijo fresco artesanal a partir de leite de cabra e concentrado de beterraba com e sem a adição de uma cultura probiótica de Lactobacillus acidophilus, caracterizando o produto obtido fisico-quimicamente e verificando sua capacidade probiótica a partir de um ajuste a um modelo matemático preditivo de crescimento microbiológico. Buscou-se, com isso, obter um novo queijo funcional capaz de agregar valor a uma matéria-prima que geralmente não é apreciada por consumidores não habituados. 


\section{REFERENCIAL TEÓRICO}

\section{Leite de cabra}

Nutricionalmente, o leite de cabra é o alimento natural mais completo conhecido entre os que são altamente compatíveis com o organismo humano. Em relação à composição, esse leite apresenta maior similaridade com o leite humano do que o leite bovino. Além disso, o leite caprino contém $30 \%$ menos colesterol e concentrações satisfatórias de vitamina A e vitaminas do complexo B (tiamina, riboflavina e niacina), além de minerais como cálcio, zinco, selênio, manganês e cobre. Esses fatores fazem com que esse produto seja indicado para o consumo como substituto do leite bovino para grupos especiais, como pessoas alérgicas, crianças e idosos (GETANEH et al., 2016; PARK; HAENLEIN; WENDORFF, 2017).

Outro fator relevante é que o leite de cabra é digerido no corpo humano em cerca de 20 minutos, enquanto o leite bovino pode levar de 2 a 3 horas (PARK; HAENLEIN; WENDORFF, 2017). A rápida digestibilidade pode ser associada a diversos fatores, como o tamanho dos glóbulos de gordura, que são menores que os do leite bovino, e o elevado teor de ácidos graxos de cadeia curta e média (GETANEH et al., 2016). Apesar disso, esses ácidos contribuem para o aroma e sabor típicos dos produtos de leite de cabra, que podem influenciar negativamente na aceitação do leite caprino e dos seus derivados por consumidores que não estão habituados aos mesmos (COSTA et al., 2015; QUEIROGA et al., 2013).

Em relação à produção, no Brasil predomina a do leite de vaca, no entanto, o leite de cabra, mesmo com o menor volume de produção, tem grande importância na geração de emprego e renda (DELGADO JÚNIOR; SIQUEIRA; STOCK, 2020). A caprinocultura brasileira é mais difundida nas regiões Norte e Nordeste, sendo o estado da Paraíba o maior produtor do país. Nesses territórios, a maior parte da produção é direcionada para programas de distribuição de alimentos, como a merenda escolar (IBGE, 2017).

$\mathrm{O}$ crescimento na demanda pelo leite de cabra e seus derivados está relacionado ao aumento da renda per capita dos consumidores e a preocupação das pessoas com relação à alimentação saudável. Assim, a comercialização desses produtos ainda se encontra em um estado inicial no país, porém, tem-se observado o aumento gradativo no consumo de queijos, iogurtes, doce de leite e outros lácteos elaborados a partir do leite caprino, já que o mesmo se apresenta como um alimento de alto valor nutritivo e com potencial funcional (MARTINS et al., 2018). 


\section{Queijos frescos}

O queijo fresco é uma classificação dada aos queijos que, logo após a fabricação, já estão pronto para o consumo, sem necessitar de um período de maturação (BRASIL, 2017). Em relação ao queijo fresco caprino, estudos têm surgido com o intuito de diferenciá-los e aumentar a sua aceitação. Novos queijos caprinos do tipo coalho, por exemplo, vem sendo desenvolvidos condimentados com cumaru, cranberry e cachaça para a verificação do aumento da aceitabilidade e comercialização de tais produtos (APOSTU et al., 2014; SOUZA et al., 2011; SILVA; COSTA; DELFINO, 2018).

Quando o queijo é obtido a partir do leite cru, não tratado termicamente, pode ser associada a denominação de artesanal (PERNAMBUCO, 2018). Os produtos obtidos a partir do leite cru desenvolvem aromas e sabores característicos dependendo da raça, da nutrição animal, do processo de fabricação e da microbiota oriunda do leite, que pode variar de acordo com a região produtora (DOLCI et al., 2008). Em relação à microbiota, estudos têm sido realizados com o intuito de identificar e caracterizar propriedades de interesse em microrganismos presentes no leite cru e nos queijos artesanais, podendo utilizá-los, por exemplo como culturas starters para serem utilizadas em outros produtos lácteos (CABRAL et al., 2016).

\section{Beterraba}

A beterraba (Beta vulgaris) é uma raiz tuberosa que pode ser utilizada para diferentes fins, como a extração de açúcares ou o consumo in natura, dependendo da variedade (PALMIERI et al., 2018). Em aspectos nutricionais, a variedade da beterraba de mesa apresenta teores significativos de vitaminas A, B1, B2 e C e de sais minerais (SANTOS, M. S.; et al., 2016).

A beterraba de mesa contém também um alto teor de betalaínas, um grupo de pigmentos hidrossolúveis constituído de betaxantinas e betacianinas (TIVELLI et al., 2011). Além da coloração, esses pigmentos possuem também efeitos benéficos à saúde, atuando, por exemplo, como antioxidante, cardioprotetor, anti-inflamatório e antimicrobiano. A concentração de betalaínas na beterraba vermelha pode variar de 70mg a 4000mg por 100g de produto, o que pode representar mais do que $2 \%$ do total de sólidos solúveis (CELLI; BROOKS, 2017; SANTOS, M. S.; et al., 2016).

As betalaínas apresentam sensibilidade ao processamento térmico, com a perda de cerca de 40\% do conteúdo original em 15 minutos de aquecimento com vapor simulando um sistema de evaporação doméstico. Apesar disso, o elevado teor inicial dos pigmentos faz com que uma 
quantidade significativa permaneça mesmo após o processamento (CELLI; BROOKS, 2017; JAGANNATH; KUMAR; RAJU, 2015).

O interesse pelas propriedades nutricionais e de pigmentação da beterraba fez com que 295 novos produtos surgissem a partir de sua incorporação. Já foram elaborados, por exemplo, biscoitos do tipo cookies e sorvetes com base láctea, levando à obtenção níveis de aceitabilidade superiores a 70\% nos dois produtos (BASSETTO et al., 2013; SANTOS, M. S.; et al., 2016). Devido a esses fatores, atualmente, além do aumento da demanda pelo consumo in natura ou na forma de snacks e sucos funcionais, a beterraba está sendo adicionada industrialmente em produtos como sopas desidratadas, iogurtes e catchups, vista como uma potencial matéria prima no mercado (PALMIERI et al., 2018).

\section{Probióticos}

Probióticos são definidos como microrganismos que têm a capacidade de atuar no equilíbrio da microbiota intestinal, gerando efeitos benéficos à saúde. Esses microrganismos podem interagir com bactérias do trato gastrointestinal ou atuar diretamente sobre o hospedeiro. Para serem aplicados em alimentos, além de produzirem o efeito benéfico e serem seguros para o consumidor, os probióticos devem ser capazes de sobreviver até atingir o local de atuação no trato gastrointestinal (BINNS, 2013).

No ramo dos produtos adicionados de probióticos, a indústria de laticínios se destaca como a que apresenta maior variedade, principalmente em iogurtes e leites fermentados. Os queijos também têm tido a incorporação de probióticos ampliada, principalmente por causa de resultados positivos na utilização do mesmo como veículo (OLIVEIRA, 2014).

A viabilidade funcional e sensorial dos probióticos tem sido estudada em diferentes tipos de queijo, incluindo o queijo de coalho e em queijos obtidos a partir do leite de cabra. Verificou-se, por exemplo, o efeito dos probióticos na constituição do perfil de ácidos graxos de queijos de cabra, o que pode resultar, por exemplo, em diferenças sensoriais dos produtos (KESENKAS et al., 2018).

Por possuírem um grande histórico de segurança para o consumo, as bactérias mais estudadas e empregadas como probióticos em alimentos são as dos gêneros Lactobacillus e Bifidobacterium. Ambas são caracterizadas como Bactérias Láticas (BL), grupo que apresenta semelhanças fisiológicas e metabólicas e têm em comum a característica de possuir ácido lático como principal produto da fermentação de carboidratos (DINEV et al., 2017). BL estão presentes naturalmente em alguns alimentos, como o leite cru, mas também podem ser adicionadas em produtos para fins tecnológicos (ALMEIDA JÚNIOR et al., 2015). 
Em relação a Lactobacillus acidophilus, essa espécie é parte natural do trato gastrointestinal do homem e de alguns animais que vem sendo utilizado como probiótico em diversos alimentos, incluindo produtos como queijos e iogurtes, devido à sua estabilidade e aos seus efeitos benéficos (GEABRA et al., 2015; PEROTTI et al., 2014).

\section{Microbiologia preditiva}

A microbiologia preditiva é um método rápido e relativamente econômico para a obtenção de estimativas confiáveis quanto ao crescimento, inativação e sobrevivência dos microrganismos em condições específicas. Assim, tanto a conservação como a manutenção de aspectos físico-químicos de um alimento constituem áreas de estudo da microbiologia preditiva (GONZÁLEZ et al., 2019; SIQUEIRA et al., 2014).

Com os modelos preditivos, parâmetros microbiológicos e matemáticos associados às equações podem ser variados de modo a ajustar as curvas de resposta aos dados obtidos. A aplicação dos modelos matemáticos primários é coerente quando são utilizadas para condições ambientais estáticas. Assim, dependendo do microrganismo, das condições e do produto, o crescimento pode ser descrito por uma equação teórica (HALL et al., 2014; SIQUEIRA et al., 2014).

O modelo de Baranyi e Roberts, por exemplo, relaciona diversos parâmetros biológicos: contagem inicial de microrganismos $\left(\mathrm{y}_{0}\right)$, taxa de crescimento máximo $\left(\mu_{\text {máx }}\right)$, tempo da fase lag $(\lambda)$ e variação entre o número máximo de microrganismos e o número inicial $(\mathrm{C})$. Com o ajuste do modelo aos dados experimentais, é possível realizar interpretações do crescimento assim como comparações entre diferentes crescimentos avaliados (BARANYI; ROBERTS, 1994).

\section{METODOLOGIA}

\section{Obtenção do leite caprino}

Todo o leite de cabra utilizado foi obtido a partir de parceria com o departamento de Zootecnia da Universidade Federal Rural de Pernambuco (UFRPE), possuidor de uma criação de caprinos, onde as cabras foram devidamente ordenhadas seguindo as Boas Práticas Agropecuárias e o leite cru foi imediatamente transportado em conteiners plásticos, para o Laboratório de Tecnologia de Produtos de Origem Animal (Leites) da Universidade Federal de Pernambuco (UFPE). 


\section{Preparo e ativação dos inóculos}

A cepa de Lactobacillus acidophilus, o probiótico adicionado em uma das formulações, foram obtidas a partir das amostras comerciais liofilizadas da empresa Globalfood (LAFTIL10). Foram preparadas culturas de trabalho com concentração de $10^{12} \mathrm{UFC} / \mathrm{mL}$ em leite previamente esterilizado, que foram armazenadas a $-22^{\circ} \mathrm{C} \pm 2^{\circ} \mathrm{C}$.

A ativação dos probióticos sob congelamento foi iniciada no dia anterior à produção dos queijos. As amostras foram armazenadas à temperatura de refrigeração $\left(6 \pm 2{ }^{\circ} \mathrm{C}\right)$ por $10 \pm 1 \mathrm{~h}$. Em seguida, as mesmas foram colocadas em Estufa Incubadora BOD, à $36 \pm 1{ }^{\circ} \mathrm{C}$, por um período de $14 \pm 1 \mathrm{~h}$.

\section{Preparo do concentrado de beterraba}

As beterrabas vermelhas (Beta vulgaris) foram obtidas em supermercados locais, selecionando os vegetais aparentemente sadios, com o mínimo de defeitos físicos, como cortes ou perfurações, com a coloração marrom-avermelhada característica da matéria prima. As beterrabas foram sanitizadas com imersão em solução de hipoclorito de sódio $1 \%$ por 30 minutos e enxaguados com água corrente por 1 minuto.

Em seguida, os vegetais higienizados foram processados com adição de água na proporção $1: 1 \mathrm{e}$, posteriormente, foram aquecidos a $100{ }^{\circ} \mathrm{C}$ por cerca de 30 minutos para a remoção parcial do conteúdo de água.

\section{Produção dos queijos artesanais}

Foram elaborados dois queijos a partir do leite de cabra cru, sendo um deles adicionado da cultura probiótica de Lactobacillus acidophilus (QP) e outro sem adição de cultura (QS). O processamento realizado foi definido utilizando como fundamento o passo a passo da produção do queijo de coalho, com as devidas adaptações (FURTADO, 2005).

Após o aquecimento inicial do leite cru a $35^{\circ} \mathrm{C}$, adicionou-se primeiramente cloreto de cálcio e, posteriormente, a enzima coagulante, ambos da marca Rica Nata®, diluídos em um pequeno volume de água destilada e seguindo as recomendações dos fabricantes quanto ao volume utilizado de cada produto.

A adição do Lactobacillus acidophilus foi realizada no próprio leite aquecido, sob agitação, momentos antes da adição do coalho, em apenas um dos ciclos produtivos. A cultura previamente ativada foi adicionada na proporção de $2 \%(\mathrm{v} / \mathrm{v})$, com concentração de $10^{12}$ $\mathrm{UFC} / \mathrm{mL}$. 
$\mathrm{Na}$ salga da massa, utilizou-se $7,700 \mathrm{~g} \pm 0,001 \mathrm{~g}$ por litro de leite utilizado. $\mathrm{Na}$ enformagem, utilizou-se formas para queijo de coalho e, para a incorporação do concentrado de beterraba, posicionou-se inicialmente uma camada de massa de queijo no fundo e nas paredes do recipiente com adição do concentrado de beterraba na proporção de $20 \%$ em relação à massa de queijo, em camada única ou em múltiplas camadas, intercaladas com camadas de massa de queijo.

\section{Ensaios Físico-Químicos}

Foram realizados ensaios físico-químicos segundo os procedimentos recomendados na IN de $\mathrm{n}^{\circ} 30$ de 2018 do MAPA, que indica os métodos analíticos físico-químicos para o controle de produtos de origem animal (BRASIL, 2018a). Assim, determinou-se a acidez por titulação com acidímetro de Dornic, o pH com o equipamento de bancada (pHmetro BEL PHS3-BW), o teor de gorduras pelo método butirométrico, o de proteínas pelo método de Kjeldahl, o de umidade e cinzas pelo método gravimétrico e, por fim, os carboidratos totais por diferença. Ressalta-se que o teor de sólidos totais é determinado a partir da subtração do teor de umidade do valor unitário (100\%) e o teor de Gordura no Extrato Seco (GES) pode ser determinado a partir da relação entre o percentual de gordura e o percentual de sólidos totais.

\section{Ensaios Microbiológicos}

Utilizou-se como base as metodologias da American Public Health Association (APHA, 2015), que descreve métodos padronizados internacionalmente para para análises microbiológicas em alimentos.

Para a verificação da segurança microbiológica dos queijos produzidos, tendo em vista que foram produzidos com leite cru, com e sem a adição de Lactobacillus acidophilus, realizouse, após a produção, a pesquisa de Salmonella spp. e Listeria monocytogenes. Também foram realizadas a identificação de Staphylococcus aureus e a contagem de coliformes termotolerantes pela técnica do Número Mais Provável.

\section{Crescimento de Bactérias Lácteas e modelagem matemática}

A enumeração de Bactérias foi realizada semanalmente em cada um dos queijos por 35 dias de armazenamento do produto a $6 \pm 2{ }^{\circ} \mathrm{C}$. A partir dos dados obtidos, foi realizado o ajuste matemático do crescimento das Bactérias Láticas ao modelo de Baranyi e Roberts com a ferramenta online DMFit (ComBase $\left.2021^{\circledR}\right)$. 


\section{RESULTADOS E DISCUSSÃO}

\section{Ensaios Físico-Químicos}

Os Ensaios Físico-Químicos dos queijos produzidos, com e sem a adição do Lactobacillus acidophilus, levaram aos resultados apresentados na Tabela 01.

Tabela 01: Valores médios e desvio padrão das características físico-química dos queijos produzidos com leite caprino cru adicionado de beterraba nas versões com (QP) e sem (QS) adição de Lactobacillus acidophilus

Característica

$\mathrm{pH}$

Acidez $\left({ }^{\circ} \mathrm{D}\right)$

Gordura (\%)

Gordura no Extrato Seco - GES (\%)

Proteínas (\%)

Carboidratos $(\%)$

Umidade (\%)

Sólidos Totais (\%)
QP

$6,77 \pm 0,01^{\mathrm{a}}$

$10,50 \pm 0,50^{\mathrm{a}}$

$15,50 \pm 0,70^{\mathrm{a}}$

$34,00 \pm 2,00^{\mathrm{a}}$

$17,40 \pm 0,01^{\mathrm{a}}$

$8,65 \pm 0,05^{\mathrm{a}}$

$54,80 \pm 0,20^{\mathrm{a}}$

$45,20 \pm 0,20^{\mathrm{a}}$

$3,65 \pm 0,04^{\mathrm{a}}$
QS

$6,70 \pm 0,04^{\mathrm{a}}$
$20,00 \pm 0,01^{\mathrm{b}}$
$15,75 \pm 0,40^{\mathrm{a}}$
$37,00 \pm 1,00^{\mathrm{b}}$
$13,80 \pm 0,01^{\mathrm{b}}$
$9,40 \pm 0,10^{\mathrm{b}}$
$57,60 \pm 0,40^{\mathrm{b}}$
$42,40 \pm 0,40^{\mathrm{b}}$
$3,40 \pm 0,10^{\mathrm{a}}$

$20,00 \pm 0,01^{\mathrm{b}}$

$15,75 \pm 0,40^{\mathrm{a}}$

$37,00 \pm 1,00^{\mathrm{b}}$

$13,80 \pm 0,01^{\mathrm{b}}$

$9,40 \pm 0,10^{\mathrm{b}}$

$42,40 \pm 0,40^{\mathrm{b}}$

$3,40 \pm 0,10^{\mathrm{a}}$

Nota: Letras diferentes numa mesma linha indicam diferença estatisticamente significativa pelo teste de Tukey ao nível de significância de 5\%.

Fonte: Própria (2020).

Os valores de $\mathrm{pH}$, umidade e GES (Tabela 01) não corresponderam aos valores médios de referência da literatura para o queijo de coalho (DUTRA, 2017). Os queijos produzidos puderam ser classificados, pela Portaria nº146 de 1996 do MAPA (BRASIL, 1996), como queijos semigordos (teor de GES entre 25 e 44,9\%) e de alta a muito alta umidade. Isso pode ter ocorrido devido à adição do concentrado de beterraba, que aumentou o conteúdo de sólidos não gordurosos e umidade em relação a um queijo de coalho comum, influenciando também no teor de cinzas dos queijos produzidos.

Em relação ao teor de proteínas, os valores encontrados (Tabela 01) condizem com o esperado para queijos, tendo em vista que esse teor é bastante variável, podendo estar em faixas de 10 a 30\% dependendo do processamento utilizado. Além disso, em uma avaliação dos queijos de coalho artesanais comercializados em Pernambuco, verificou-se valores de 8,38\% a $25,63 \%$ para o teor de proteínas (LIMA et al., 2017).

Através da comparação entre os queijos, apesar de terem havido variações estatisticamente significativas entre os produtos com e sem a adição de probióticos, inferiu-se que tais alterações são decorrentes do fato de que foi realizada uma produção artesanal em 
pequena escala que, portanto, está propensa a variações.

Apesar disso, percebeu-se que a maior alteração em termos numéricos aconteceu no teor de acidez dos produtos (Tabela 01), mesmo que ambos estejam próximos a valores encontrados para queijos de coalho comerciais (SANTOS, B.M.; et al., 2011; SOUZA; ALVES; OLIVEIRA, 2016). O resultado encontrado, em que QS apresentou um teor de acidez mais elevado, não era esperado, pois a adição da cultura probiótica em QP deveria promover o aumento da produção de ácido lático e, consequentemente, o aumento da acidez. Apesar disso, como se trata de um queijo elaborado com leite cru, a microbiota endógena pode ter favorecido o aumento da acidez em QS, fato que pôde ser ratificado pelo estudo da concentração de Bactérias Láticas que será posteriormente abordado.

\section{Ensaios Microbiológicos do queijo}

Os Ensaios Microbiológicos realizados nos queijos produzidos permitiram classificar os produtos QS e QP como de acordo com os padrões microbiológicos definidos pela legislação brasileira (BRASIL, 2019), tendo em vista que não foram detectados Salmonella spp., estafilococos coagulase positivos ou Coliformes termotolerantes. Além disso, também não foi detectada a presença de Listeria monocytogenes, ratificando a segurança microbiológica do leite caprino cru utilizado.

\section{Crescimento de Bactérias Lácteas}

A partir do ajuste matemático dos dados de crescimento de Bactérias Lácteas durante o armazenamento a $6 \pm 2{ }^{\circ} \mathrm{C}$ por 35 dias ao modelo matemático de Baranyi e Roberts no programa online DMFit ${ }^{\circledR}$, foram obtidos os parâmetros microbiológicos relativos aos dois queijos produzidos que são apresentados na Tabela 03. Além disso, tal ajuste matemático permitiu a geraração de uma curva preditiva de ajuste aos dados experimentais, que é mostrada na Figura 01.

Tabela 03: Parâmetros do ajuste ao modelo de Baranyi e Roberts do crescimento de Bactérias Láticas durante o armazenamento a $6 \pm 2{ }^{\circ} \mathrm{C}$ por 35 dias dos queijos de leite caprino com beterraba produzidos com (QP) e sem (QS) a adição de cultura probiótica de Lactobacillus acidophilus

\section{Parâmetro matemático}

QP

QS

Valor inicial - $\mathrm{y}_{0}\left(\log \mathrm{UFC} . \mathrm{g}^{-1}\right)$

$6,744 \pm 0,128$

$6,660 \pm 0,190$

Valor final $-\mathrm{y}_{\mathrm{f}}\left(\log\right.$ UFC. $\left.\mathrm{g}^{-1}\right)$

$11,861 \pm 0,900$

$12,192 \pm 0,238$

Duração da fase lag - $\lambda$ (dias)

$5,443 \pm 1,630$

$5,136 \pm 1,649$

Taxa de crescimento máxima - $\mu_{\text {máx }}\left(\log\right.$ UFC. $\left.\mathrm{g}^{-1} \cdot \mathrm{dia}^{-1}\right)$

$0,158 \pm 0,012$

$0,224 \pm 0,020$

Fonte: Própria (2019). 
Figura 01: Ajuste ao modelo de Baranyi e Roberts do crescimento de Bactérias Láticas durante o armazenamento a $6 \pm 2{ }^{\circ} \mathrm{C}$ por 35 dias dos queijos de leite caprino com beterraba produzidos com (QP) e sem (QS) a adição de cultura probiótica de Lactobacillus acidophilus

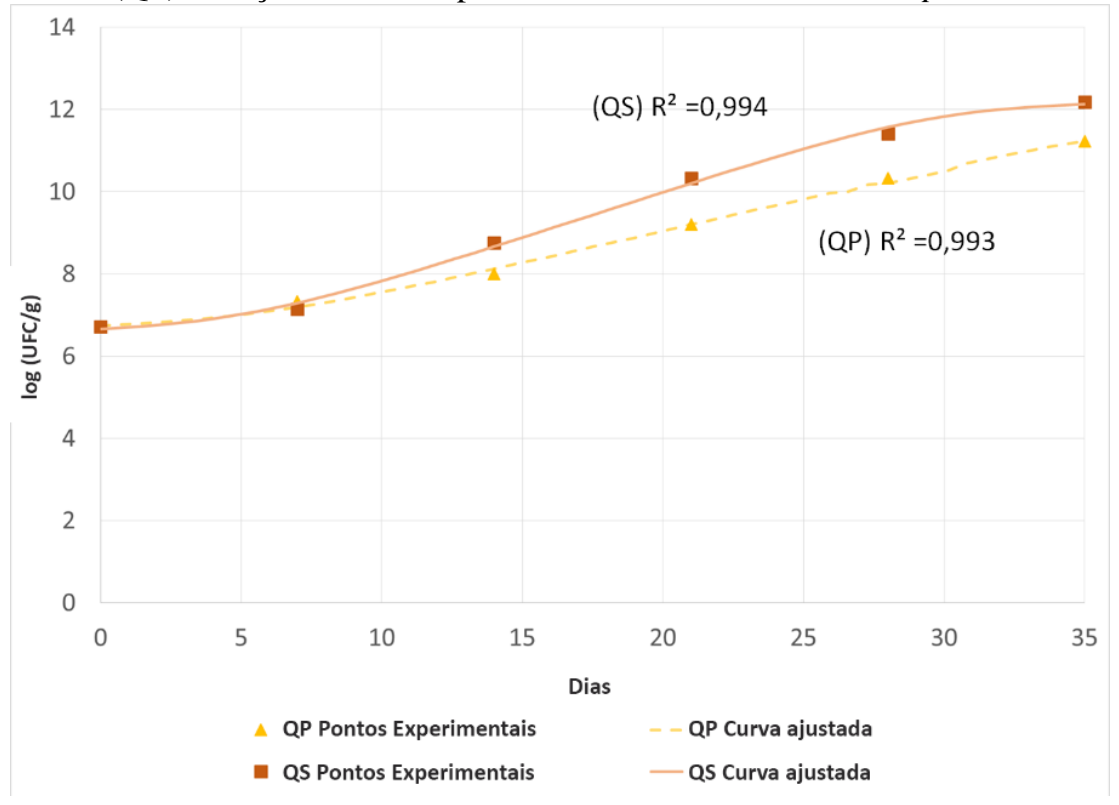

Fonte: Própria (2019)

A legislação brasileira define que a caracterização de um produto como adicionado de probióticos deve ser embasada por estudos científicos que definam o número e a espécie do microrganismo necessárias para a obtenção de um efeito benéfico ao consumidor (BRASIL, 2018b). Pela literatura, a quantidade de Báctérias Lácteas em queijos que possuem alegação de probióticos contêm um número de microrganismos superior a $10^{7} \mathrm{UFC}_{\mathrm{g}} \mathrm{g}^{-1}$ (HOMAYOUNI et al., 2018; LEITE et al., 2021). Devido a isso, ambos os produtos (QS e QP) puderam ser classificados como probióticos a partir da primeira semana de armazenamento.

Em relação ao ajuste matemático realizado, percebeu-se que os parâmetros encontrados, assim como o gráfico relativo ao crescimento, foram similares para os dois produtos. Apesar disso, uma taxa de crescimento máxima e um valor final de microrganismos maiores foram obtidos no queijo sem adição de probióticos (QS). Esse resultado não era esperado tendo em vista que a adição inicial da cultura probiótica de L. acidophilus no queijo QP deveria promover um aumento significativo dos parâmetros de crescimento das Bactérias Láticas na matriz do queijo.

Isso pode ser justificado devido ao fato de que foi utilizado queijo caprino cru, portanto, há uma microbiota endógena presente em QS, que já possuía uma adaptação natural ao leite de cabra, sem que houvesse uma possível competição com uma cultura adicionada, como pode ter ocorrido em QP. Ressalta-se que BL fazem parte da microbiota natural do leite caprino, 
composta principalmente melos microrganismos dos gêneros Lactobacillus, Streptococcus, Lactococcus, Leuconostoc e Enterococcus (HERNÁNDEZ-SALDAÑA et al., 2016).

\section{CONSIDERAÇÕES FINAIS}

A partir do projeto desenvolvido, foi possível produzir queijos artesanais probióticos utilizando leite de cabra e concentrado de beterraba com e sem adição de uma cultura probiótica de Lactobacillus acidophilus, com parâmetros físico-químicos e microbiológicos condizentes ao produto.

Quanto ao crescimento de Bactérias Láticas, os produtos com e sem adição de cultura probiótica foram caracterizados como funcionais a partir da primeira semana do período de armazenamento avaliado. Portanto, a adição da cultura de Lactobacillus acidophilus, que representa um custo associado ao processo, não contribuiu significativamente na caracterização do produto como probiótico, pois o queijo obtido com leite cru, rico em bactérias láticas nativas, apresentou resultado superior em relação à concentração de Bactérias Láticas, benéficas para o consumidor.

\section{REFERÊNCIAS}

APHA - American Public Health Association. Compendium of Methods for the Microbiological Examination of Foods. 5th ed. [S. l.]: APHA Press, 2015.

APOSTU, S.; POP, C.; ROTAR, A. M.; SALANŢ̌̆, L.; POP, A.; GĂVRUŞ, I. Improving the Chemical and Sensory Characteristics of Goat Cheese by the Addition of Cranberry. Bulletin of University of Agricultural Sciences and Veterinary Medicine Cluj-Napoca. Food Science and Technology, vol. 71, no. 2, p. 1-2, 2014.

BARANYI, J.; ROBERTS, T. A. A dynamic approach to predicting bacterial growth in food. International Journal of Food Microbiology, vol. 23, no. 3-4, p. 277-294, 1994.

BASSETTO, R. Z.; SAMULAK, R.; MISUGI, C.; BARANA, A.; ROSSO, N. Produção de biscoitos com resíduo do processamento de beterraba (Beta vulgaris L .). Revista Verde de Agroecologia e Desenvolvimento Sustentável, , p. 139-145, 2013.

BINNS, N. Ilsi Europe Concise Monograph Series: Probióticos , Prebióticos e a Microbiota Intestinal. ILSI Europe - International Life Sciences Institute, , p. 1-35, 2013.

BRASIL. Decreto n ${ }^{0} 9.013$ de 29 de março de 2017, Regulamento de Inspeção Industrial e Sanitária de Produtos de Origem Animal. Ministério da Agricultura, Pecuária e Abastecimento. Brasília, 2017. 
BRASIL. Instrução Normativa $\mathrm{N}^{\circ}$ 60, de 23 de dezembro de 2019. Listas de padrões microbiológicos para alimentos prontos para oferta ao consumidor. Brasilia, 2019.

BRASIL. Instrução Normativa ${ }^{\circ} 30$ de 26 de Junho de 2018. Oficializa os métodos constantes 303 do Manual de Métodos Oficiais para Análise de Alimentos de Origem Animal. Brasília, 2018a.

BRASIL. Portaria $\mathrm{n}^{0} 146$ de 07 de março de 1996. Aprova os regulamentos técnicos de identidade e qualidades dos produtos lácteos. Brasília, 1996.

BRASIL. Resolução da Diretoria Colegiada RDC N ${ }^{\circ}$ 241, de 26 de Julho de 2018. Dispõe sobre os requisitos para comprovação da segurança e dos benefícios à saúde dos probióticos para uso em alimentos. Brasília, 2018b.

CABRAL, M. L. B.; LIMA, M. dos S. F. de; FERNANDES, G. A. de A.; COSTA, E. F. da; PORTO, A. L. F.; CAVALCANTI, M. T. H. Queijos artesanais: fonte de bactérias ácido láticas selvagens para formulação de fermentos tradicionais. Journal of bioenergy and food science, vol. 3 , no. 4, p. 207-215, 2016.

CELLI, G. B. .; BROOKS, M. S. Impact of extraction and processing conditions on betalains and comparision of properties with anthocyanins - a current review. Food Research International, vol. 100, p. 501-509, 2017.

COSTA, M. P.; BALTHAZAR, C. F.; RODRIGUES, B. L.; LAZARO, C. A.; SILVA, A. C. O.; CRUZ, A. G.; CONTE JUNIOR, C. A. Determination of biogenic amines by highperformance liquid chromatography (HPLC-DAD) in probiotic cow's and goat's fermented milks and acceptance. Food Science and Nutrition, vol. 3, no. 3, p. 172-178, 2015.

DE ALMEIDA JÚNIOR, W. L. G.; FERRARI, Í. da S.; DE SOUZA, J. V.; DA SILVA, C. D. A.; DA COSTA, M. M.; DIAS, F. S. Characterization and evaluation of lactic acid bacteria isolated from goat milk. Food Control, vol. 53, p. 96-103, 2015.

DINEV, T. .; BEEV, G. .; DENEV, S. .; DERMENDZHIEVA, D. .; TZANOVA, M. .; VALKOVA, E. Antimicrobial activity of Lactobacillus acidophilus against patogenic and food spoilage microorganisms: a review. Agricultural Science and Technology, vol. 9, no. 1, p. 39, 2017.

DOLCI, P. .; ALESSANDRIA, V. .; ZEPPA, G. .; RANTSIOU, K. .; COCOLIN, L. Microbiological characterization of artisanal Raschera PDO cheese: Analysis of its indigenous lactic acid bacteria. Food Microbiology, vol. 25, no. 2, p. 392-399, 2008.

DOS SANTOS FALCÃO DE LIMA, M.; DA SILVA, R. A.; DE LIMA FILHO, J. L.; PORTO, A. L. F.; CAVALCANTI, M. T. H. Queijo de coalho artesanal: fonte alternativa de peptídeos antimicrobianos. Brazilian Journal of Food Technology, vol. 20, 2017.

DUTRA, E. R. P. Fundamentos Básicos da Produção de Queijos. Juiz de Fora: Templo, 2017.

FAKRUDDIN, M.; MAZUMDAR, R. M.; MANNAN, K. S. Bin. Predictive microbiology: Modeling microbial responses in food. Ceylon Journal of Science (Biological Sciences), vol. 40, no. 2, p. 121, 2012. 
FURTADO, M. M. Quesos Típicos de Latinoamerica. São Paulo: Danisco A/S, 2005.

GARCIA, R. V.; TRAVASSOS, A. E. R. General aspects of goat milk: a review. Revista do Instituto de Laticínios Cândido Tostes, vol. 67, no. 386, p. 81-88, 2012.

GEABRA, C. .; RIBEIRO, M. C. E. .; CHAVES, K. S. .; GANDARA, A. L. N. .; GIGANTE, M. L. Cheese, Effectiveness of different methodologies for the selective enumeration of Lactobacillus acidophilus La5 from yoghurt and Prato. LWT-Food Science and Technology, vol. 64, no. 1, p. 508-513, 2015.

GETANEH, G. .; MEBRAT, A. ; WUBIE, A. ; KENDIE, H. Review on Goat Milk Composition and its Nutritive Value. Journal of Nutrition and Health Sciences, vol. 3, no. 4, 2016.

GONZÁLEZ, S. C.; POSSAS, A.; CARRASCO, E.; VALERO, A.; BOLÍVAR, A.; POSADAIZQUIERDO, G. D.; GARCÍA-GIMENO, R. M.; ZURERA, G.; PÉREZ-RODRÍGUEZ, F. 'MicroHibro': A software tool for predictive microbiology and microbial risk assessment in foods. International Journal of Food Microbiology, vol. 290, no. July 2018, p. 226-236, 2019.

HALL, B. G. .; ACAR, H. .; NANDIPATI, A. .; BARLOW, M. Growth Rates Made Easy. Molecular biology and evolution, vol. 31, no. 1, p. 232-238, 2014.

HERNÁNDEZ-SALDAÑA， O. F.; VALENCIA-POSADAS， M.; DE LA FUENTESALCIDO, N. M.; BIDESHI, D. K.; BARBOZA-CORONA, J. E. Bacteriocinogenic Bacteria Isolated from Raw Goat Milk and Goat Cheese Produced in the Center of México. Indian Journal of Microbiology, vol. 56, no. 3, p. 301-308, 2016.

HOMAYOUNI, A.; ANSARI, F.; AZIZI, A.; POURJAFAR, H.; MADADI, M. Cheese as a Potential Food Carrier to Deliver Probiotic Microorganisms into the Human Gut: A Review. Current Nutrition \& Food Science, vol. 16, no. 1, p. 15-28, 2018.

JAGANNATH, A.; KUMAR, M.; RAJU, P. S. Fermentative Stabilization of Betanin Content in Beetroot and Its Loss during Processing and Refrigerated Storage. Journal of Food Processing and Preservation, vol. 39, no. 6, p. 606-613, 2015.

KESENKAS, H.; ERGONUL, P. G.; AKAN, E.; KINIK, Ö. Effect of some pro and prebiotics on fatty acid and organic acid composition of symbiotic goat cheese. Carpathian Journal of Food Science and Technology, vol. 10, no. 1, p. 111-124, 2018.

LEITE, A. C. S.; CORTEZ, N. M. D. S.; DE ALBUQUERQUE, S. S. M. C.; SHINOHARA, N. K. S.; MACEDO, I. M. E.; ANDRADE, S. A. C. Development of stuffed coalho cheese in the traditional, lactose-free and probiotic-added formulations. Ciencia Rural, vol. 51, no. 5, 2021.

LEITE DE SOUZA, E.; VIEIRA DA COSTA, A. C.; FERNANDES GARCIA, E.; GOMES DE OLIVEIRA, M. E.; HAUSS DE SOUZA, W.; RAMOS DO EGYPTO QUEIROGA, R. de C. Qualidade do queijo de leite de cabra tipo Coalho condimentado com cumaru (Amburana cearensis A.C. Smith). Brazilian Journal of Food Technology, vol. 14, no. 03, p. 220-225, 2011. 
MARTINS, I. B. A.; DELIZA, R.; DOS SANTOS, K. M. O.; WALTER, E. H. M.; MARTINS, J. M.; ROSENTHAL, A. Viability of Probiotics in Goat Cheese During Storage and Under Simulated Gastrointestinal Conditions. Food and Bioprocess Technology, vol. 11, no. 4, p. 853-863, 2018.

OLIVEIRA, L. de. Probióticos, prebióticos e simbióticos: definição, benefícios e aplicabilidade industrial. Fundação Centro Tecnológico de Minas Gerais: Serviço Brasileiro de Respostas Técnicas, 2014.

PALMIERI, F. G. .; MARCOMINI, L. R. S. .; BARBIERI, M. G. .; SOUZA, M. N. O. de. Pequenos mercados, grandes oportunidades: agora é a vez da abóbora, abobrinha, beterraba, caqui, coco, pepino e pêssego. Hortifruti Brasil, Escola Superior de Agricultura Luiz de Queiroz - Universidade de São Paulo, Piracicaba, 2018.

PARK, Y. W. .; HAENLEIN, G. F. W. .; WENDORFF, W. L. Handbook of milk of nonbovine mammals. 2nd ed. Oxford: Blackwell Publishing Professional, 2017.

PERNAMBUCO. Lei $\mathrm{n}^{0}$ 16.312, de 11 de Janeiro de 2018. Dispõe sobre o processo de Produção Artesanal do Queijo Coalho e outros produtos derivados do Leite. Recife, 2018.

PEROTTI, M. .; WOLF, I. .; ADDIS, M. .; COMUNIAN, R. .; PABA, A. .; MEINARDI, C. Incorporation of probiotic bacteria (Lactobacillus and Bifidobacterium spp.) in Argentiean ovine cheese. Dairy Science \& Technology, vol. 94, no. 94, p. 225-267, 2014.

QUEIROGA, R. C. R. E. .; SANTOS, B. M. .; GOMES, A. M. P. .; MONTEIRO, M. J. .; TEIXEIRA, S. M. ;; SOUZA, E. L. .; PEREIRA, C. J. D. .; PINTADO, M. M. E. Nutritional, textural and sensory properties of Coalho cheese made of goats', cows' milk and their mixture. LWT - Food Science and Technology, vol. 50, p. 538-544, 2013.

SANTOS, B. M. .; OLIVEIRA, M. E. G. .; SOUSA, Y. R. F. .; MADUREIRA, A. R. M. F. M. .; PINTADO, M. M. E. .; GOMES, A. M. P. Caracterização físico-química e sensorial de queijo de coalho produzido com mistura de leite de cabra e de leite de vaca. Revista do Instituto Adolfo Lutz, vol. 70, no. 3, 2011.

SANTOS, M. S. .; CARVAlHO, C. B. .; KEMPINSKI, E. C. .; ANTIGO, J. L. D. .; MADRONA, G. S. Avaliação da qualidade de sorvete de leite com diferentes concentrações de beterraba. Brazilian Journal of Surgery and Clinical Research, vol. 13, no. 3, p. 17-21, 2016.

SARTORIO, M.; SANTOS, D. O. S.; CARVALHO, C. B.; CARVALHO, E.; LORAINE, J.; ANTIGO, D.; MADRONA, G. S. Quality and Sensorial Evaluation of Milk Ice Cream Made With Differ- Ent Concentrations of Beet. vol. 13, p. 17-21, 2016.

SILVA, V. B. da; COSTA, M. P. da; DELFINO, N. D. C. Aceitabilidade E Intenção De Compra Do Queijo De Coalho De Cabra Temperado Com Cachaça. Revista do Instituto de Laticínios Cândido Tostes, vol. 72, no. 3, p. 121-130, 2018.

SIQUEIRA, A. A.; CARVALHO, P. G. S. de; MENDES, M. L. M.; SHIOSAKI, R. K.; SIQUEIRA, A. A.; CARVALHO, P. G. S. de; MENDES, M. L. M.; SHIOSAKI, R. K. 
MicroFit: a free software for the development and fit of mathematical models for bacterial growth. Brazilian Journal of Food Technology, vol. 17, no. 4, p. 329-339, 2014.

SLATNAR, A. .; STAMPAR, F. .; VEBERIC, R. .; JAKOPIC, J. HPLC-MS identification of 306 betalain profile of different betroot (Beta vulgaris L. ssp. vulgaris) parts and cultivars. Journal of Food Science, vol. 80, p. 1952-1958, 2015.

SOUKOLIS, C. .; BEHBOUDI-JOBBEHDAR, S. ;; YONEKURA, L. .; PARMENTER, C. .; FISK, I. Impact of milk protein type on the viability and storage stability of microencapsuled Lactobacillus acidophilus NCIMB 701748 using spray drying. Food and Bioprocess Technology, vol. 75, no. 2, p. 1255-1268, 2014.

SOUZA, D. L. M.; ALVES, J. E. A.; OLIVEIRA, C. A. Avaliação fisico-quimica do queijo coalho artesanal e industrial fabricado em Salgueiro - PE. Anais I Congresso Internacional das Ciências Agrárias, 2016.

TIVELLI, S. W. .; FACTOR, T. L. .; TERAMOTO, J. R. S. .; FABRI, E. G. .; MORAES, A. R. A. de; TRANI, P. A. .; MAY, A. Beterraba: do plantio à comercialização. Campinas: Boletim Técnico Instituto Agronômico - IAC, n. 210, 2011. 